\title{
URE-LOCKERS: Inibição da Urease com Terapias de Nova Geração
}

$\bullet \bullet \bullet$
O uso generalizado de antibióticos de largo espectro tem contribuído para o aumento de resistência microbiana a antibióticos. Esta situação é particularmente preocupante em infeções por Helicobacter pylori que requerem tratamentos com múltiplos antibióticos por períodos prolongados. Estima-se que metade da população humana adulta tenha sido colonizada por esta bactéria que, para sobreviver no estômago, requer a metaloproteína urease para converter ureia em amónia e carbonato que, por sua vez, neutralizam o ácido no ambiente em torno da bactéria. Direcionar um tratamento contra esta enzima é, por conseguinte, uma alternativa com elevado potencial. Contudo, a descoberta de moléculas que inibam eficazmente este alvo tem sido limitada. Isto deve-se, em grande parte, à dificuldade de encontrar moléculas inibidoras que sejam estáveis no ambiente hidrolítico do estômago, assim como também devido a tempos de residência limitados e à baixa seletividade para a urease, o que causa efeitos secundários. Neste contexto, é urgente que se desenvolvam novas abordagens de desenho de inibidores da urease da H. pylori que apresentem um balanço equilibrado entre afinidade e estabilidade. Os estudos realizados pela nossa equipa multidisciplinar levaram à descoberta de que dendrímeros de poliureia possuem a notável capacidade de ligação ao local ativo da urease de Canavalia ensiformis (vulgo feijão-cutelo ou fava-rica). Estes polímeros ramificados, produzidos por metodologias sustentáveis, são resistentes em meio acídico e podem também ser modificados quimicamente nos seus ramos terminais. Assim, este projeto está focado em desenvolver uma abordagem de triagem in silico e teste de modificações dos grupos terminais dos dendrímeros de poliureia para encontrar novos inibidores específicos da urease. Iremos ainda caracterizar a sua estabilidade, toxicidade e atividade inibitória em modelos in vitro e in vivo.
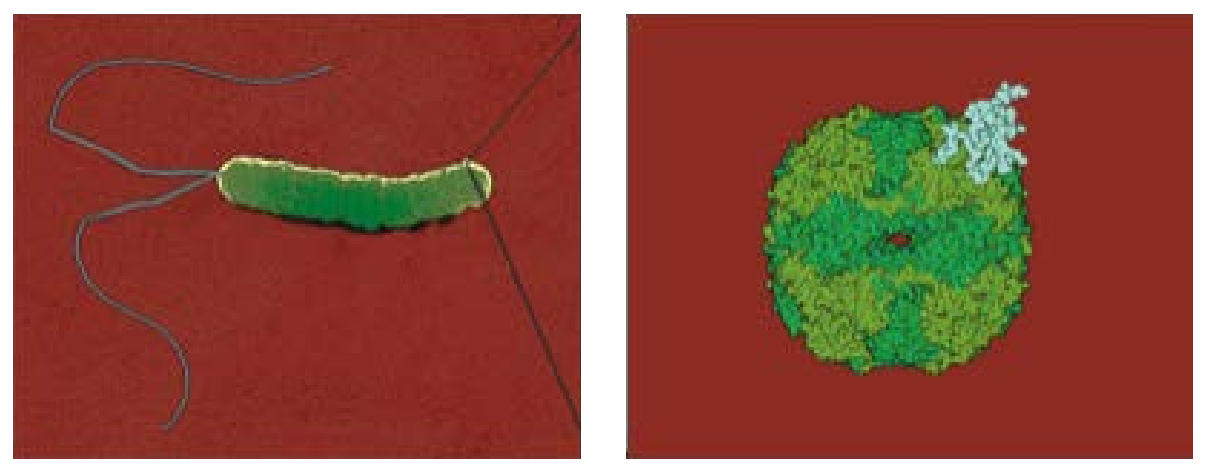

Estabilidade no estômago

Inibição molecular específica

Elevado tempo de resistência

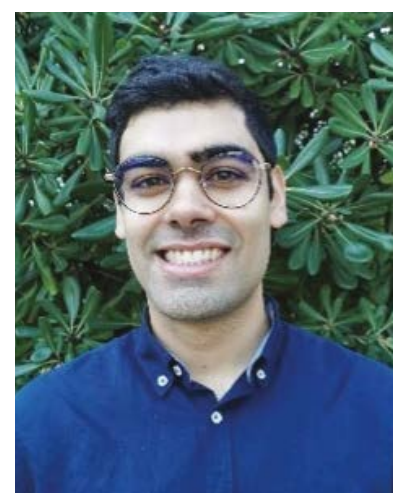

$>$

Ficha Técnica do Projeto

\section{Nuno Martinho}

Referência: PTDC/MED-QUI/3542/2020.

Financiamento: Fundação para a Ciên-

cia e a Tecnología (FCT).

Equipa: IBB/IST/Universidade de Lisboa

- Nuno Martinho (IR), Vasco D. B. Bonifácio

(Co-IR), Sandra Pinto, Dalila Mil-Homens,

Adriana Cruz; iNOvA4Health/Universidade

Nova de Lisboa - Jacinta Serpa 